\title{
¿EI juez conoce el Derecho? Algunos aspectos controversiales con relación a la aplic ación del principio de iura novit curia en el proceso civil(*)
}

\author{
Does the judge know the law? Some controversial aspects concerning the \\ application of iura novit curia principle in the Peruvian civil process
}

\author{
Rafael Prado Bringas ${ }^{(*)}$ \\ Perú - Universidad de Lima \\ Francisco Zegarra Valencia ${ }^{(* * *)}$ \\ Perú - Estudio Rodríguez Angobaldo
}

\begin{abstract}
Resumen: A través de este artículo académico, los autores desarrollan el fundamento y límites del principio de iura novit curia en el proceso civil peruano, a efectos de poder dar respuestas prácticas a los principales problemas que conlleva su aplicación por parte del juez. Así, explican por qué un adecuado entendimiento del principio iura novit curia no puede conllevar a que el juez emita sentencias en base a causales jurídicas que no han sido debidamente delimitadas en la demanda, y que hayan constituido materia de debate por las partes en el proceso. Finalmente, señalan por qué la aplicación del principio iura novit curia no permite que el juez pueda emitir fallos sorpresas, es decir, aquellos basados en fundamentación jurídica que no ha sido parte de la controversia en el proceso.
\end{abstract}

Palabras clave: lura Novit Curia - Derecho a la Tutela Jurisdiccional Efectiva - Principio de Congruencia - Decisiones sorpresa - Derecho Procesal Civil - Sistema Romano

\begin{abstract}
In this academic work, the authors look into the foundations and limitations of the iura novit curia principle in the Peruvian civil procedure, in order to give practical responses to the main challenges faced by judges in its application. Moreover, they explain that a good understanding of such principle should not permit a judge to submit a judgment based on legal causes that were not duly invoked and defined by the claimant, or that have not been discussed by the parties during the procedure. Finally, they propose that the application of the iura novit curia principle does not allow judges to render a "surprise decision" based on a legal argument that was not part of the controversy in the procedure.
\end{abstract}

Keywords: lura Novit Curia - Right to Effective Judicial Protection - Congruency Principle - Surprise Decision - Procedural Civil Right - Civil Law

$\left({ }^{*}\right) \quad$ Nota del Editor: este artículo fue recibido el 15 de setiembre de 2019 y su publicación fue aprobada el 27 de octubre de 2019.

$\left({ }^{* *}\right) \quad$ Abogado por la Pontificia Universidad Católica del Perú. Máster en Argumentación Jurídica por la Universidad de Alicante. Profesor de Derecho Procesal Civil y de Técnicas de Litigación en la Universidad de Lima y Universidad Peruana de Ciencias Aplicadas UPC. Contacto: rprado@rpb.pe.

$\left({ }^{* * *}\right)$ Abogado por la Pontificia Universidad Católica del Perú (PUCP). Título de segunda especialidad en Derecho Procesal y estudios de maestría en Derecho Procesal por la PUCP. Postgrado en especialización en procesal civil, arbitraje y medicación por la Universidad de Salamanca. Adjunto de docencia del curso Derecho Procesal Civil II de la Universidad de Lima y Revisión e Impugnación Judicial en la PUCP. Miembro del Grupo de Investigaciones de Derecho Procesal Crítico y Constitución de la PUCP (GIDEPROC). Asociado del estudio Rodríguez Angobaldo Abogados. Miembro extraordinario de lus et Veritas. Contacto: fzegarra@er.com.pe. 


\section{Introduc ción}

De acuerdo con el Art. II ${ }^{(1)}$ del Título Preliminar del Código Procesal Civil Peruano (en adelante, CPC), el juez se encuentra a cargo de la dirección del proceso y tiene a su vez el deber de impulsarlo. A partir de este rol de dirección en el proceso es que el juez debe procurar maximizar los derechos sustanciales y procesales de las partes, a efectos de que estas puedan conseguir tutela jurisdiccional efectiva a través de una sentencia de mérito que resuelva el conflicto de intereses o que elimine la incertidumbre jurídica. Como bien señala Eugenia Ariano Deho, no debemos olvidar que "el proceso es el instrumento de tutela de concretas situaciones jurídicas de ventaja; el proceso civil es instrumento al servicio de quien tiene la razón" (2003, pág. 6).

A pesar de lo anterior, en ciertas ocasiones los jueces hacen uso de su rol de directores del proceso de manera indebida, sin darse cuenta que en su afán de solucionar un conflicto lo hacen en menoscabo de los derechos de las partes, lo que termina repercutiendo en el núcleo mismo del derecho a la tutela jurisdiccional efectiva. Una de estas ocasiones es cuando los jueces hacen una indebida aplicación del principio del iura novit curia en aras de adecuar la tutela a la solución del conflicto de intereses intersubjetivo de un caso concreto. En efecto, no en pocas ocasiones este principio es usado con la intención de brindar justicia al caso concreto, sin tomar en cuenta lo que constituye objeto del proceso o su objeto de debate; y con ello, menoscabando las garantías del proceso, lo que finalmente desvirtúa la finalidad de su uso y lo convierte en un instrumento de desigualdad entre las partes.

Debido a ello, es que mediante el presente artículo trataremos algunos inconvenientes que trae la aplicación del principio de iura novit curia en nuestro sistema procesal. Específicamente, abordaremos los problemas generados por pretensiones genéricas, ambiguas o imprecisas; así como los problemas que se originan por las sentencias que contienen un fundamento jurídico que nunca fue objeto de debate del proceso, los que se denominan comúnmente como decisione della terza vía o también sentenze a sorpresa.

Para ello, abordaremos los principales límites del principio de iura novit curia en nuestro ordenamiento procesal, así como el fundamento de estos límites, lo que nos permitirá otorgarle una posible solución a los inconvenientes que presenta su aplicación sin el debido cuidado.
Con lo que desarrollaremos no pretendemos darle una respuesta definitiva a un problema tan complejo como lo constituye la aplicación del principio de iura novit curia en nuestro sistema procesal, siendo nuestro propósito incentivar el debate $y$, sobre todo, proponer mecanismos de solución que permitan a los diversos operadores jurídicos percibir que la mejor manera de solucionar un conflicto es garantizando el respeto de los derechos de las partes en el proceso.

\section{El principio de Iura Novit Curia: concepto y fundamento}

El aforismo lura Novit Curia se encuentra positivizado en nuestro ordenamiento procesal en el artículo VII del Título Preliminar del CPC, el cual establece lo siguiente: "el Juez debe de aplicar el derecho que corresponda al proceso, aunque no haya sido invocado por las parte o lo haya sido erróneamente. Sin embargo, no puede ir más allá del petitorio ni fundar su decisión en hechos diversos de los que han sido alegados por las partes".

La obligación del juez de aplicar la fundamentación jurídica adecuada al caso concreto constituye un principio del proceso, pues "actúa como un deber impuesto a los jueces de resolver los litigios utilizando el derecho, es decir, de sujetarse a este, lo que implica conocer (El juez 'debe conocer' el derecho)" (Ezquiaga, 2000, pág. 18).

Este principio se deriva del derecho de toda persona a la tutela jurisdiccional efectiva, sin importar la correcta calificación jurídica que haya realizado de los hechos. Inclusive, garantiza la aplicación de diversos principios de la función jurisdiccional, tales como el sometimiento del juez a la Constitución y las leyes (Art. 138 (2) de la Constitución), y la

(1) Artículo II del Título Preliminar del Código Procesal Civil: "Principios de dirección e impulso del proceso Fines del proceso o integración de la norma procesal. "La dirección del proceso está a cargo del Juez, quien la ejerce de acuerdo a lo dispuesto en este Código. El Juez debe impulsar el proceso por sí mismo, siendo responsable de cualquier demora ocasionada por su negligencia. Están exceptuados del impulso de oficio los casos expresamente señalados en este Código".

(2) Artículo 138 de la Constitución Política del Perú. "La potestad de administrar justicia emana del pueblo y se ejerce por el Poder Judicial a través de sus órganos jerárquicos con arreglo a la Constitución y a las leyes. En todo proceso, de existir incompatibilidad entre una norma constitucional y una norma legal, los jueces prefieren la primera. Igualmente, prefieren la norma legal sobre toda otra norma de rango inferior". 
prohibición de sentencias non liquet (Art 139, inciso $8^{(3)}$ de la Constitución).

El derecho a la tutela jurisdiccional efectiva no se limita a que todas las personas puedan acceder al fuero jurisdiccional, sino que abarca la posibilidad de que puedan acceder a una sentencia que resuelva el fondo de la controversia y que la misma pueda ser ejecutada (Montero Aroca, Gómez Colomer y Barona Villar, 2014, pág. 210). Para ello el proceso requiere estar diseñado en base a técnicas procesales capaces de atender el derecho material (Marinoni, 2007, pág. 177). Una de estas técnicas lo constituye el principio de iura novit curia, pues al ser el juez el representante del Estado en un proceso, tiene el deber de conocer el ordenamiento jurídico, pues "las normas existen o no, independiente de que las partes la aduzcan y la conformidad entre ellas no puede crearlas" (Montero et al., 2014, pág. 265).

Como señala el profesor Monroy Gálvez: "el iura novit curia constituye un deber del juez. El aforismo se sustenta en una presunción que tiene la calidad de iuris et iure, es decir, que no admite prueba en contrario. También se sustenta en un presupuesto de hecho, la presunción es que el juez conoce el derecho. El presupuesto de hecho es que las partes no están obligadas a una calificación jurídica de sus pretensiones. Por tanto, si se presume que el juez conoce el derecho, atendiendo al objetivo final del proceso, se concluye que tiene el deber de aplicar al proceso el derecho que corresponda" (2010, pág. 59).

De lo anteriormente glosado es que resultaría suficiente que el demandante realice una petición al órgano jurisdiccional sustentada en determinados hechos a efectos que esta tenga que ser atendida ("Da mihi factum, dabo tibi ius"). De ahí que si bien el CPC establece como requisito de la demanda que se señale la fundamentación jurídica en la que se sustenta (artículo 424 inciso $7^{(4)}$ del CPC), esta es pasible de subsanación en caso no se haya hecho referencia de la misma (artículo 426 inciso $1^{(5)}$ del CPC).

Finalmente, conviene señalar que este deber que tiene el juez de aplicar la norma correcta al caso concreto puede conllevar a tres consecuencias:

“a) Aunque las dos partes del proceso estén de acuerdo en admitir la existencia de una norma que realmente no existe, el juez no podrá tenerla en cuenta, b) Aunque las dos partes del proceso estén de acuerdo en silenciar la existencia de una norma que realmente existe, el Juez no podrá dejarla de aplicar; y, c) El juez puede alterar la calificación jurídica de los hechos efectuada por las partes siempre que no implique una mutación de los elementos objetivos de la demanda" (Ezquiaga, 2002, pág. 28).

\section{Límites a la aplic ación del principio de iura novit curia}

El deber del juez de aplicar el derecho correcto al caso concreto tiene su límite en los derechos constitucionales de las partes. De ahí que el derecho a la tutela jurisdiccional efectiva sirve de fundamento del principio de iura novit curia, y a su vez, constituye su límite.

Así, como pasaremos a demostrar, existen dos límites a la aplicación del principio de iura novit curia en el proceso civil: (i) que el juez respete que le corresponde exclusivamente a las partes definir el objeto del proceso, así como su objeto de debate (principios de congruencia e imparcialidad); y, (ii) el respeto irrestricto del derecho de defensa de las partes, que implica además un mandato al juez de garantizar el contradictorio durante las distintas etapas del proceso.

\subsection{Principios de congruencia e imparcialidad} Como sabemos la libertad del juez de poder subsumir los hechos alegados y probados por las partes dentro del encuadre legal que corresponda encuentra su limitación en el principio dispositivo y, debido a ello, las disposiciones legales encuentran sentido en tanto sean entendidas en su aplicación a determinados hechos incorporados al proceso por las partes.

Así, el derecho a la tutela jurisdiccional efectiva se materializa cuando a iniciativa de parte se promueve el proceso (Art. IV ${ }^{(6)}$ del Título Preliminar de CPC). De ahí que Gonzáles señale lo siguiente:

(3) Artículo 139 de la Constitución Política del Perú. "Son principios de la función jurisdiccional: (...) 8. El principio de no dejar de administrar justicia por vacío o deficiencia de la ley. En tal caso, deben aplicarse los principios generales del derecho y el derecho consuetudinario".

(4) Artículo 424 del Código Procesal Civil: "Requisitos de la demanda. La demanda se presenta por escrito y contendrá: (...) 7. La fundamentación jurídica del petitorio".

(5) Artículo 426 del Código Procesal Civil: "Inadmisibilidad de la demanda. El Juez declara inadmisible la demanda cuando: 1. No tenga los requisitos legales".

(6) Artículo IV del Título Preliminar del Código Procesal Civil: "Principios de Iniciativa de parte y de Conducta procesal. - El proceso se promueve solo a iniciativa de parte, la que invocará interés y legitimidad para obrar. No requieren invocarlos el Ministerio Público, 
"La acción domina la percepción de obtención de justicia, esto es, que la libertad individual, ecualizada en un escenario constitucional frente al poder estatal, hará del proceso no solo un método de solución de conflictos, sino de desenvolvimiento libertario del ciudadano" (2013, pág. 671).

Conforme lo desarrollado, el derecho a la tutela jurisdiccional efectiva garantiza a su vez que sean las personas que acudan al proceso las que tengan el control de lo que piden, y por tanto, de lo que se resuelva. Por ello es importante nunca descuidar ni perder de vista el principio de congruencia, pues "constituye la máxima expresión del principio dispositivo” (Ariano, 2003, pág. 8).

El control que tienen las partes no se limita a lo pedido en la demanda (o lo pedido en la reconvención) y lo que se resuelve, sino que además se extiende a lo que constituye materia de debate en el proceso. El objeto del proceso lo constituye la pretensión de la demanda (o reconvención), mientras que el objeto de debate lo constituyen aquellos puntos controvertidos en razón a los hechos alegados por el demandado en su contestación (o los hechos alegados por el demandante en su escrito de contestación de reconvención). Así, tal como señala Montero et al.:

"La determinación concreta del interés cuya satisfacción se solicita de los órganos jurisdiccionales es facultad exclusiva de las partes; la determinación del objeto del proceso corresponde al actor mediante la pretensión y la determinación del objeto del debate al demandado por medio de la resistencia" (2014, pág. 387).

Inclusive, conviene resaltar que la potestad que tienen las partes en la delimitación del objeto del proceso y del objeto de debate tiene a su vez distintas implicancias en el proceso, dado que en el supuesto que el juez ejerza sus poderes de juzgamiento fuera de dichos límites, conllevaría a diversas afectaciones adicionales a la afectación del principio dispositivo, tales como: (i) la afectación al derecho a la cosa juzgada, en caso exista una sentencia predecesora sobre un extremo que no era parte de la controversia, (ii) la afectación a la proscripción de litispendencia, pues el demandante o el demando iniciaron un proceso sobre el extremo que tampoco era parte de la controversia; y, (iii) la afectación del derecho de defensa y de prueba, ya que las partes no tendrían la posibilidad de defenderse sobre el extremo que conformó la controversia.

De lo anterior se desprende que el límite del juez a aplicar las normas pertinentes al caso concreto lo constituye el principio de congruencia, pues este "obliga a los órganos judiciales a resolver las pretensiones de las partes de manera congruente con los términos en que vengan planteadas, sin cometer, por lo tanto, desviaciones que supongan modificación o alteración del debate procesal" (STC No. 4295-2007-PHC, fundamento 8). En esa misma línea, se ha señalado que mediante este principio se busca que: "(i) el juez no pueda omitir pronunciarse respecto a lo debatido por las partes, (ii) tampoco pueda conferir un remedio o una defensa si las partes no la han formulado; (iii) dar más allá de lo que estrictamente fue pedido; o (iv) menos de lo que las partes han aceptado" (Priori, 2019, pág. 122).

Asimismo, la limitación que tiene el juez al momento de aplicar el principio de iura novit curia encuentra su fundamento en el principio de imparcialidad, pues la potestad del juez de modificar el debate procesal en cualquiera de sus extremos es incompatible con el rol que tiene en el proceso.

El principio de imparcialidad no se encuentra reconocido de manera expresa en nuestra Constitución; sin embargo, el Tribunal Constitucional ha señalado que esta omisión "no ha impedido reconocer en él a un derecho implícito que forma parte de un derecho expreso. A saber, del derecho al debido proceso, reconocido en el inciso 3) del artículo $139^{\circ}$ de la Constitución" (STC No. 6149-2006PA, fundamento 48). Debido a lo anterior, el máximo intérprete de la Constitución ha señalado que mediante este principio se garantiza la "independencia del juez frente a las partes y el objeto del proceso mismo. De este modo, ambas deben ser entendidas como una totalidad, por lo que no puede alegarse el respeto al principio de independencia mientras existan situaciones que generen dudas razonables sobre la parcialidad de los jueces" (STC No. 2465-2004-PA, fundamento 9).

En virtud a lo señalado, no cabe duda que si el juez modificara el objeto del proceso o el objeto de debate estaría realizando un accionar incompatible con su rol de tercero imparcial, ya que "si el juez pudiera aportar hechos atentaría a la misma esencial de lo que es un proceso civil, pues con ello se estaría convirtiendo en parte. (...) lo que

el procurador oficioso ni quien defiende intereses difusos. Las partes, sus representantes, sus Abogados y, en general, todos los partícipes en el proceso, adecuan su conducta a los deberes de veracidad, probidad, lealtad y buena fe. El Juez tiene el deber de impedir y sancionar cualquier conducta ilícita o dilatoria". 
impide esa aportación es la existencia de funciones o papeles incompatibles en el proceso. En este cada uno de los sujetos que intervienen en él tiene un papel que cumplir y la mezcla de esos papeles llevaría a que el juez, bien adoptara el papel de parte (si investigara los hechos para aportarlos), bien asumiera el papel de testigo (si ha tenido conocimiento de los mismos extrajudicialmente). Juez y parte y juez y testigos son papeles incompatibles" (Montero et al. 2014, pág. 263).

Por ello, es que la norma que recoge el principio de iura novit curia en nuestro ordenamiento procesal civil (Art. VII ${ }^{(7)}$ del Título Preliminar del CPC) establece que este tiene su limitación en el objeto del proceso, específicamente en el petitum, y en los hechos que son materia de debate. Como vemos la norma establece dos limitaciones: (i) la proscripción de ir más allá del petitorio, y (ii) la proscripción de incorporar al proceso hechos no invocados por las partes. Naturalmente estas prohibiciones involucran además la obligación de pronunciarse sobre lo que es objeto del proceso y los hechos incorporados por las partes.

La proscripción de ir más allá del petitorio implica que el juez no puede variar o modificar el mismo. El petitorio o petitum constituye el pedido expreso y concreto de lo que el demandante busca y exige al órgano jurisdiccional. Es decir, "el objeto de la pretensión lo constituye el determinado efecto jurídico perseguido (cosa o bien y el derecho o relación jurídica que se pretende) y, por tanto, la tutela que se reclama" (Echandía, 1961, pág. 219).

El petitorio está integrado por un objeto inmediato, que es la clase de pronunciamiento que se solicita (la solicitud de una cierta actuación jurisdiccional); y el objeto mediato, que es el bien jurídico perseguido, la relación jurídica cuya existencia o inexistencia deba declararse. A resumidas cuentas, según señala Montero et al. (2014) lo siguiente:

"La petición inmediata, que atiende a la actuación jurisdiccional y que ha de referirse a un tipo de tutela jurisdiccional, consistente en juzgar, en decir el derecho en el caso concreto. (...) La petición mediata, que atiende siempre a un bien jurídico al que se refiere al tutela judicial, dado que esta no se pide ni puede prestarse sin referencia a un bien" (pág. 152).
Atendiendo a lo señalado, queda claro que en virtud a este límite en la configuración del principio de iura novit curia, el Juez no pueda modificar o variar la clase de tutela jurídica que el demandante solicita, y el bien jurídico o el derecho que reclame.

La proscripción de incorporar hechos no invocados por las partes garantiza que el juez no tenga la posibilidad de agregar hechos principales o secundarios, así como el deber del juez de pronunciarse sobre los hechos que ambas partes incorporen al proceso. Los hechos principales son "acontecimientos de la vida que suceden en un momento en el tiempo y que tienen trascendencia jurídica; esto es, hechos que son el supuesto de una norma que les atribuye consecuencias jurídicas" (Montero et al., 2014, pág. 262). Por otro lado, los hechos secundarios son aquellos que "no reciben calificación jurídica alguna. Estos hechos adquieren significado en el proceso solo si de ellos se puede extraer algún argumento acerca de la verdad o falsedad de un enunciado sobre un hecho principal" (Taruffo, 2005, pág. 120).

Los hechos son incorporados por el demandante mediante su demanda y por el demandado mediante su contestación, en tanto amplíe la queastio facti. Así, el demandante debe presentar los hechos en los que sustenta su demanda (artículo 424 inciso $6^{(8)}$ del CPC), pudiendo tener la posibilidad de ampliarlos hasta antes de la notificación de la misma (artículo $428^{(9)}$ del CPC).

El demandado tendrá la posibilidad de admitir o negar los hechos alegados por el demandante (Art. 442 inciso $2^{(10)}$ del CPC), y tiene la posibilidad de ampliar los hechos sobre los cuales versará el objeto de debate

(7) Artículo VII del Título Preliminar del Código Procesal Civil: "Juez y Derecho. El Juez debe aplicar el derecho que corresponda al proceso, aunque no haya sido invocado por las partes o lo haya sido erróneamente. Sin embargo, no puede ir más allá del petitorio ni fundar su decisión en hechos diversos de los que han sido alegados por las partes".

(8) Artículo 424 del Código Procesal Civil: "Requisitos de la demanda. La demanda se presenta por escrito y contendrá: (...) 6. Los hechos en que se funden el petitorio, expuestos enumeradamente en forma precisa, con orden y claridad".

(9) Artículo 428 del Código Procesal Civil: "Modificación y ampliación de la demanda. El demandante puede modificar la demanda antes que esta sea notificada. Puede, también, ampliar la cuantía de lo pretendido si antes de la sentencia vencieran nuevos plazos o cuotas originadas en la misma relación obligacional, siempre que en la demanda se haya reservado tal derecho. A este efecto, se consideran comunes la ampliación los trámites precedentes y se tramitará únicamente con un traslado a la otra parte".

(10) Artículo 442 del Código Procesal Civil: "Requisitos y contenido de la contestación de la demanda. Al contestar el demandado debe: (...) 2. Pronunciarse respecto de cada uno de los hechos expuestos en la demanda. El silencio, la respuesta evasiva o la negativa genérica pueden ser apreciados por el Juez como reconocimiento de verdad de los hechos alegados". 
a través de su escrito de contestación de demanda (artículo 442 inciso $4^{(11)}$ del CPC).

Una vez superadas estas etapas procesales, en aplicación del principio de preclusión que rige nuestro ordenamiento procesal civil, la única posibilidad de incorporar hechos se encuentra limitada a la incorporación de hechos nuevos (Art. $429^{(12)}$ del CPC), lo cuales podrán ser incorporados hasta antes de concluida la etapa postulatoria o mediante el escrito de apelación de sentencia (Art. 374(13) del CPC) y deberán referirse a hechos nuevos y relevantes para el derecho o interés discutido. Citando a la profesora Ariano Deho (2013):

"Debe de tratarse de hechos verificados con posterioridad al momento en que el demandante interpuso su demanda o que el demandado contestó (los llamados nova producta). Siendo 'blandos' podríamos considerar que los hechos 'nuevos' también son aquellos que son conocidos por la parte con posterioridad al planteamiento de la demanda o de la contestación (los llamados nova reperta)" (pág. 108).

Los hechos que delimitarán el objeto del debate serán aquellos alegados por el demandante que tengan la capacidad de dar origen a la consecuencia jurídica que requiere, así como los hechos incorporados por el demandado en los que sustente su defensa. Nótese en este punto que lo importante es que nos encontremos ante hechos con relevancia jurídica, pues "el hecho, no está dado por sí mismo y autónomamente antes de que asuma relevancia jurídica. En el proceso ese hecho lo que se define como tal en función de la norma aplicable para decidir la controversia" (Taruffo, 2005, pág. 92).

Los hechos jurídicos en los que sustenta el demandante su postura son ampliamente conocidos como hechos constitutivos, los cuales son definidos como "el supuesto de la norma cuya alegación hace el demandante como base de la existencia jurídica que pide" (Montero et al. 2014, pág. 314).

En dicho contexto entonces, y siguiendo la dialéctica del proceso, el demandado podrá negar los hechos constitutivos del demandante o defenderse mediante la alegación de hechos modificativos, extintivos, impeditivos o excluyentes. Sobre el particular, Nieva Fenoll (2015) enseña que:
"Hechos extintivos son los que extinguen la obligación, como el pago, la caducidad o la compensación. Hechos impeditivos son los que dejan subsistente teóricamente la obligación, pero impiden su cumplimiento al hacer acaecido un vicio del consentimiento como el dolo o el error. Hechos excluyentes serían los que dejan incólume también la obligación hasta su cumplimiento, pero abandonan dicho cumplimiento en las exclusivas manos del deudor, quien no puede ser obligado al mismo y, por tanto, puede excluirse" (pág. 154).

De lo anterior, podemos constatar que el principio de iura novit curia encuentra su límite en los principios de congruencia e imparcialidad, que garantizan que el juez deba pronunciarse sobre lo que constituye objeto del proceso o lo que constituye el objeto de debate, sin poder modificar, agregar o ignorar los hechos constitutivos incorporados por el demandante, y el demandado en caso de reconvención, ciertamente, y los hechos negativos, impeditivos, extintivos o modificativos incorporados por el demandado.

\subsection{El derecho de defensa y el principio de contradicción}

En la praxis judicial se solía entender que el derecho de defensa de las partes no se encontraba afectado cuando el juez empleaba el iura novit curia al juzgar, dado que ese derecho no incluía la posibilidad de que las partes pudieran resguardarse de los poderes oficiosos del juez, sino únicamente la posibilidad del demandado de defenderse de la demanda interpuesta en su contra.

El derecho de defensa se entendía como la contrapartida del derecho de acción del demandante, entendido como "una expresión

(11) Artículo 442 del Código Procesal Civil: "Requisitos y contenido de la contestación de la demanda. Al contestar el demandado debe: (...) 4. Exponer los hechos en que funda su defensa en forma precisa, ordenada y clara".

(12) Artículo 429 del Código Procesal Civil: "Medios probatorios extemporáneos. Después de interpuesta la demanda, solo pueden ser ofrecidos los medios probatorios referidos a hechos nuevos y a los mencionados por la otra parte al contestar la demanda o reconvenir. De presentarse documentos, el Juez concederá traslado a la otra parte para que dentro de cinco días reconozca o niegue la autenticidad de los documentos que se le atribuyen".

(13) Artículo 374 del Código Procesal Civil: "Medios probatorios en la apelación de sentencia. Solo en los procesos de conocimiento y abreviados las partes o terceros legitimados pueden ofrecer medios probatorios en el escrito de formulación de la apelación o en el de absolución de agravios, y únicamente en los siguientes casos: 1. Cuando los medios probatorios estén referidos a la ocurrencia de hechos relevantes para el derecho o interés discutido, pero acaecidos después de concluida la etapa de postulación del proceso; y, 2. Cuando se trate de documentos expedidos con fecha posterior al inicio del proceso, o que comprobadamente no se hayan podido conocer y obtener con anterioridad. Es inimpugnable la resolución por la que el superior declara inadmisibles los medios probatorios ofrecidos. Si fueran admitidos, se fijará fecha para la audiencia respectiva, la que será dirigida por el Juez menos antiguo, si el superior es un órgano colegiado". 
del derecho a la tutela jurisdiccional. Esto significa que el derecho de contradicción tiene las mismas características del derecho de acción. En consecuencia, estamos ante un derecho de naturaleza constitucional, además, subjetivo, público, abstracto y autónomo, que permite a un sujeto de derechos emplazado exigirle al Estado le preste tutela jurisdiccional efectiva" (Monroy, 2009, pág. 518).

Debido a ello, el legislador procesal entendió que se tutelaba este derecho con la sola posibilidad abstracta del demandado de tener la posibilidad de defenderse contra la demanda interpuesta en su contra. Es decir, se satisfacía, según señala Echandía (1966):

"Plenamente desde el momento en que al demandado se le cita al juicio y se le da la oportunidad de defenderse, aunque para ello no es necesario que asuma una actitud de resistencia u oposición a la demanda, ni que concurra a hacer valer sus defensas y excepciones, porque esto mira ya a las diversas maneras como ese derecho puede ser ejercitado" (pág. 214).

Así, al tomar como base esta concepción del derecho de defensa, mientras existiese la posibilidad del demandado de ser oído no se atentaba contra este derecho, en tanto este estuviese garantizado con "el hecho de realizar alegaciones, probarlas y obtener una sentencia motivada que demuestre que se ejerció el derecho de defensa" (Nieva, 215, pág. 140).

Esta concepción del derecho de defensa ha sido de alguna manera perfeccionada en la actualidad precisamente a partir del desarrollo de instituciones procesales afines que en su evolución nos obligan a entender a este derecho como un algo más complejo de la manera como era entendido en los primeros años de nuestra ley procesal.

El derecho de defensa no solo garantiza que en el proceso el demandado tenga las posibilidades abstractas de defenderse contra la demanda interpuesta en su contra, sino en que el proceso se encuentre diseñado mediante una "estructura contradictoria" (Liebman, 1980, pág. 8).

Esta exigencia materializa el principio de contradicción en el proceso que a su vez impone un mandato al legislador, y también al juez, a efectos de que "regule el proceso, cualquier proceso, partiendo de la base de que las partes han de disponer de plenas facultades procesales para tender a conformar la resolución que debe dictar el órgano jurisdiccional" (Montero et al. 2014, pág. 246).

En base a lo anterior, lo que realmente debe garantizar el derecho de defensa lo constituye la posibilidad real de las partes (y no solo del demandado) de tener la capacidad, en un escenario de igualdad de armas, de poder persuadir al juzgador en cualquier tipo de decisión que implique la disposición de algún derecho procesal o sustantivo en el proceso. Este derecho "no solo está relacionado a la necesidad de que las partes puedan ejercer el derecho a defender sus pretensiones al mismos tiempo que contradicen las pretensiones de la contraparte, sino también con el hecho de que la idea del contradictorio es que se permita la participación con el fin de influenciar, especialmente como mecanismo político-legal de control del poder jurisdiccional" (Zufaleto, 2017, pág. 23).

En nuestro ordenamiento constitucional, el derecho de defensa se encuentra establecido en el artículo 139 inciso 14 de la Constitución cuando señala que constituye un principio de la función jurisdiccional "el principio de no ser privado del derecho de defensa en ningún estado del proceso".

Sobre el mismo, el Tribunal Constitucional ha establecido que la garantía de este derecho, en el ámbito civil, no se limita a que el demando tenga la posibilidad de contestar la demanda, sino que "se proyecta como un principio de contradicción de los actos procesales que pudieran repercutir en la situación jurídica de algunas de las partes de un proceso o de un tercero con interés" (STC No. 5871-2005-PA, fundamento 12). En esa línea, también ha señalado que: "garantiza a los justiciables, en la protección de sus derechos y obligaciones, cualquiera que sea su naturaleza (civil, penal, laboral, etc.), no queden en estado de indefensión. En tal sentido, el contenido esencial del derecho de defensa queda afectado cuando cualquiera de las partes resulta impedida, por actos concretos de los órganos judiciales, de ejercer los medios necesarios, suficientes y eficaces para defender sus derechos e intereses legítimos" (STC No. 1231-2002-PHC, fundamento 2).

Conforme se desprende de lo señalado por el máximo intérprete de la Constitución, el derecho de defensa abarca en el proceso un ámbito mucho más amplio que garantizar la sola posibilidad del demandado de poder defenderse en igualdad de armas contra la demanda interpuesta en su contra. El derecho de defensa garantiza un modelo de organización del proceso en donde las partes puedan ejercer el contradictorio en cada ocasión en la que el juez tenga que decidir sobre sus derechos sustanciales o procesales.

Lo anterior incluye a su vez la posibilidad de las partes de poder influenciar sobre 
¿El juez conoce el Derecho? Algunos aspectos controversiales con relación a la aplicación del principio de iura novit curia en el proceso civil

Does the judge know the law? Some controversial aspects concerning the application of iura novit curia principle in the Peruvian civil process

la aplicación de los poderes oficiosos que pudiese utilizar el juez. Debido a lo anterior, es que con justa razón se ha señalado que:

\begin{abstract}
"Conocer de oficio no es lo mismo que juzgar de oficio, o juzgar sin previo contradictorio. El hecho de que haya, en el derecho procesal, un conjunto de materias que, en función de la relevancia procesal que poseen, autorizan que el juez las conozca independientemente de la petición de las partes - materias que, en expresión ya superada, eran también llamadas materias de orden público -, permite solamente que el juez plantee la discusión sobre estas cuestiones, con el fin de estimular el debate entre las partes que se preparan para el juzgamiento. En resumen, conocer de oficio, sí, pero juzgar sin el contradictorio, no" (Zufaleto, 2015, pág. 23).
\end{abstract}

Evidentemente, el contradictorio en determinados actos procesales podría ser restringido o incluso postergado; sin embargo, como toda restricción que involucre derechos, esta deberá seguir los cánones de la razonabilidad y a su vez ser proporcional a los derechos o bienes jurídicos por cuya tutela se restringe.

Conforme a lo anterior, al tener el legislador y el juez la obligación de organizar el proceso mediante una estructura contradictoria, se tiene también la obligación de aplicar el principio de iura novit curia de manera que no afecte el derecho de defensa de las partes, salvo que exista una justificación proporcional para ello.

\section{Principales problemas derivados de la aplicación del principio de iura novit curia y sus posibles soluciones}

Habiendo desarrollado los principales límites de la aplicación del iura novit curia en el proceso civil, corresponde hacer referencia a dos principales problemas que hemos identificado, derivados de su aplicación. Estos son los siguientes: (i) las pretensiones genéricas, imprecisas o ambiguas; y, (ii) la decisión sorpresa.

\subsection{Las pretensiones genéricas, imprecisas o ambiguas}

Existen determinados casos en los que el petitorio de la demanda se encuentra redactado de manera genérica imprecisa o ambigua, por lo que las supuestas consecuencias jurídicas solicitadas por el demandante podrían ser el resultado de la aplicación de diversas causales jurídicas establecidas en la norma.

Así, por ejemplo, tenemos los casos en los que se presenta demanda de nulidad de acto jurídico sin hacer referencia a una determinada causal, o se hace referencia a varias de ellas de manera genérica. Las demandas de divorcio que se plantean de manera genérica en las que los hechos podrían ser relacionados a diversas causales. Y las demandas de indemnización en las que no se establece claramente si son por responsabilidad contractual o extracontractual, por poner alguno de los ejemplos más comunes.

En estos casos es importante que la delimitación del petitorio se realice a través de los hechos constitutivos que integren la causa petendi de la demanda. Para ello, es necesario que se encuentren debidamente establecidos los hechos identificadores de la pretensión, aquellos que nos permitirán distinguir una pretensión de otra.

La identificación del petitorio, y por tanto del objeto del proceso, es de suma importancia porque permitirá al demandado realizar una defensa idónea, con todo lo que ello involucra; permitiendo a su vez al juez delimitar el objeto de debate del proceso. En efecto, "la calificación jurídica inicial del actor centra los términos fácticos del debate, de modo que alterar dicha calificación en el fallo entraña alterar dichas coordenadas al versar la sentencia sobre hechos en torno no giraba la controversia" (Ormazábal, 2007, pág. 115).

Así por ejemplo, de la identificación exacta de las causales en las que se sustenta una demanda de nulidad de acto jurídico, de divorcio, o la identificación del régimen de responsabilidad civil, dependerán los hechos en los que se sustente la contestación de la demanda, los medios probatorios que el demandado presente, así como la estrategia con la que aborde el proceso.

Inclusive, existen razones de orden público procesal que exigen que las causales en las que se sustente un determinado petitorio se encuentren determinadas con exactitud. La existencia de un petitorio genérico, ambiguo o impreciso podría generar la vulneración del principio de imparcialidad, pues el juez podría suplantar la actividad que tiene que realizar el demandante y enfocar la demanda desde una perspectiva que no haya sido la desarrollada por el demandante; o sobre la cual no realizó una argumentación sólida.

Pensemos en los casos en los que se interpone una demanda de nulidad de acto jurídico por la causal de falta de manifestación de voluntad y fin ilícito; sin embargo, en los fundamentos de esta solo se desarrolla el supuesto de falta de manifestación de voluntad. De permitirse un petitorio así de genérico sin que exista una integración 
adecuada entre el petitorio con los hechos identificadores desarrollados como fundamentos, podría existir la posibilidad de que el demandado se enfoque en negar y contradecir la demanda en el aspecto relacionado a la falta de manifestación de voluntad; y por su parte el juez termine optando por amparar por la causal de fin ilícito, sin que a su juicio ello genere una modificación del petitorio.

Además, hay que tener en cuenta que de la identificación del objeto del petitorio y del objeto de debate del proceso dependerá que se tutelen otras garantías del proceso, tales como la proscripción de litispendencia y la garantía de la cosa juzgada.

Debido a lo desarrollado, existen diversos mecanismos procesales en el Código Procesal Civil que permitirán al juez y al demandado poder controlar, y exigir, un petitorio claro y preciso. Estos son los siguientes: (i) el análisis de admisibilidad y procedencia in limine de la demanda, (ii) mediante la excepción de oscuridad y ambigüedad en el modo de proponer la demanda; y, (iii) en la fijación de puntos controvertidos.

El control in limine de la demanda, a pesar de constituir un análisis de oficio de la relación jurídico procesal que no es vinculante y en algunos casos hasta vulnerador al derecho a la tutela jurisdiccional efectiva (Ariano \& Priori, 2009, pág. 114), permite al juez declarar la inadmisibilidad de la demanda cuando el petitorio se encuentre incompleto o impreciso (Art. 426 inciso $\left.3^{(14)}\right)$.

De esta manera, el juez podrá requerir al demandante precisar su petitorio atendiendo a los hechos constitutivos de su demanda, especialmente aquellos identificadores de su pretensión. Así, por ejemplo, en los casos en los que el demandante requiera una indemnización sin señalar el régimen de responsabilidad, el juez puede requerir que precise el petitorio y determine si la indemnización se refiere al régimen de responsabilidad contractual o extracontractual.

Una vez admitida y notificada la demanda, el demandado puede requerir la precisión del petitorio mediante la interposición de una excepción de oscuridad y ambigüedad en el modo de interponer la demanda (Art. 446 inciso $4^{(15)}$ del CPC). A través de esta excepción lo que se busca es que se permita identificar "con precisión y seguridad las personas involucradas en el reclamo, o el objeto que se pretende o los hechos que valen de título o causa a pedir" (Alsina, 1958, pág. 112).
La identificación del petitorio es importante para la delimitación del objeto del proceso y del objeto del debate. De ahí que la relevancia de la excepción de oscuridad y ambigüedad en el modo de interponer la demanda se encuentre en que constituye el mecanismo idóneo para requerir, y obligar, al demandante precisar el petitorio de su demanda y delimite las causales en las que se sustenta.

Inclusive, una adecuada identificación del elemento subjetivo de la pretensión es relevante porque permitirá delimitar las pretensiones de la demanda. En efecto, en los casos de litisconsorcio necesario pasivo existe una sola pretensión contra varios sujetos, quienes actúan en comunidad de suerte, mientras que en los casos de litisconsorcio facultativo existirán tantas pretensiones como sujetos demandados en el proceso (Prado et al., 2016, pág. 304) Así, por ejemplo, pueden existir casos en los que exista acumulación objetiva subjetiva de pretensiones, imputándoles a cada uno responsabilidad por hechos particulares, lo cual generará un litisconsorcio facultativo y pretensiones independientes; y casos en los que se demande a varias personas alegando la existencia de responsabilidad solidaria por un hecho particular; lo cual generará que exista una sola pretensión y un litisconsorcio necesario como demandado.

La excepción de oscuridad y ambigüedad constituye una excepción dilatoria que no concluye el proceso. La estimación de esta excepción permite al demandante subsanar la demanda en el plazo establecido por el juez, y solo en el supuesto en que no se cumpla con subsanar la demanda se da por concluido el proceso (Art. 451 inciso $3^{(16)}$ del CPC).

La técnica procesal establecida por nuestro legislador para regular esta excepción no es la más idónea, ya que la norma procesal no

(14) Artículo 426 del Código Procesal Civil: "Inadmisibilidad de la demanda. El juez declarará inadmisible la demanda cuando: (...) 3. El petitorio sea incompleto o impreciso".

(15) Artículo 446 del Código Procesal Civil: "Excepciones proponibles. El demandado solo puede interponer las siguientes excepciones: (...) 4. Oscuridad y ambigüedad en el modo de interponer la demanda".

(16) Artículo 451 del Código Procesal Civil: "Efecto de las excepciones. Una vez consentido o ejecutoriado el auto que declara fundada alguna de las excepciones enumeradas en el Artículo 446, el cuaderno de excepciones se agrega al principal y produce los efectos siguientes: (...) 3 Suspender el proceso hasta que el demandante subsane los defectos señalados en el auto resolutorio y dentro del plazo que este fije, si se trata de la excepción de oscuridad o ambiguedad en el modo de proponer la demanda. Vencido los plazos a los que se refieren los incisos anteriores sin que se cumpla con lo ordenado, se declarará la nulidad de lo actuado y la conclusión del proceso". 
establece que sucede una vez que el demandante cumpla con subsanar la demanda. Este defecto no debería ser impedimento para que el juez sea respetuoso con el derecho de defensa y el principio de contradicción, y permita al demandado volver a presentar su escrito de contestación de demanda en base a los términos expuestos en el escrito de subsanación de demanda.

Que se permita al demandado presentar una nueva contestación de demanda constituye una garantía de que este pueda ejercer su derecho de defensa de manera idónea; inclusive, del derecho a la igualdad de armas. $Y$ es que de manera previa a que esta excepción se ampare, el demandando no tenía certeza de lo que constituía objeto de la pretensión y objeto de debate del proceso, razón por la que su contestación primigenia no habría sido la más eficiente e idónea. Además, si el demandante ha tenido la oportunidad de mejorar su demanda, es lógico que el demandado también tenga la oportunidad de mejorar su contestación.

Finalmente, una vez que se determine la existencia de una relación jurídica procesal válida mediante el auto de saneamiento, la última oportunidad para fijar de manera exacta el objeto del petitorio lo constituiría la fijación de los puntos controvertidos.

\section{Los puntos controvertidos según Palacio (1996):}

"Son aquellos hechos invocados por las partes como sustento de sus petitorios y que son discutidos por ellos; o que no siendo admitidos ni negados por aquel contra quien se alegan, el juez realiza la apreciación de verdad de los mismos y requiere formar convicción, o aquellas cuestiones de puro derecho cuya distinta versión o percepción o entendimiento por las partes las distancia y ocasiona debate" (pág. 157).

La delimitación del petitorio mediante la fijación de puntos controvertidos, de la manera como se encuentra legislada, no es lo más idónea; sin embargo, consideramos plausible que esta pueda realizarse mediante la exclusión de determinadas causales invocadas en la demanda y la posterior convalidación de ello (Art. 172(17) del CPC). A resumidas cuentas, si el demandante no impugna esta decisión, se entenderá que existe una renuncia tácita a que constituya objeto del proceso el análisis de determinadas causales invocadas en su demanda.

Así, por ejemplo, si el demandante solicita la nulidad de acto jurídico por fin ilícito y falta de manifestación de voluntad y el juez al momento de fijar los puntos controvertidos determina que solo se analizará la nulidad por falta de manifestación de voluntad, se entenderá que el demandante convalidó la reducción o reconducción de su petitorio en caso no interponga recurso de apelación contra esa decisión.

\subsection{La decisión sorpresa}

La libertad que tiene el juez de aplicar la norma jurídica pertinente al caso concreto puede conllevar a supuestos en los cuales el juez sin salirse del petitorio y de las alegaciones fácticas afirmadas por las partes, se pronuncie sobre un aspecto jurídico que no ha sido materia del debate. Esto es lo que se conoce como "sentenze a sorpresa" o "decisione della terza vía".

La decisión sorpresa ha sido definida según Zufaleto (2017) como lo siguiente:

"Una decisión fundada en premisas que no fueron objeto del debate previo o respecto de las cuales no se tomó conocimiento previo alguno en el proceso en el que se dictó. Es decir, la decisión es una sorpresa cuyos fundamentos no fueron mencionados en el proceso o respecto de aquellos casos donde no se ha dado la oportunidad de pronunciarse previamente. Es una decisión que sorprende a todo el mundo al pronunciarse, porque nadie - excepto quien la emitió - ha tenido la oportunidad de tomar conocimiento previo de sus fundamentos. En otras palabras, es una decisión que no ofrecía de manera previa la posibilidad de conocimiento o expresión de sus fundamentos" (pág. 31).

Así, por ejemplo, pueden darse casos en los que el demandante interpone una determinada pretensión sustentada en el fundamento jurídico " $A$ ", el demandado se defiende alegando que no existe las condiciones para que se aplique el fundamento jurídico " $A$ "; sin embargo, el juez falla a favor del demandando alegando que el petitorio no es amparable en base al fundamento jurídico " $B$ ".

Si bien se entiende que esta clase de decisiones no afectaría el principio de congruencia, pues la decisión podría enmarcarse dentro del objeto del petitorio y el objeto del debate ${ }^{(18)}$, lo cierto es que implicaría una decisión amparada en un extremo que no fue materia de contradicción en el proceso, razón por la cual afectaría el derecho de defensa y el principio de contradicción.

(17) Artículo 172 del Código Procesal Civil: "Principios de Convalidación, subsanación o integración". (...) Existe convalidación tácita cuando el facultado para plantear la nulidad no formula su pedido en la primera oportunidad que tuviera para hacerlo (...)".

(18) Entendemos que en algunas ocasiones afectaría también el principio de congruencia, en cuyo caso su impugnación sería mucho más sencilla. 
En ese sentido, si bien el juez tiene la potestad de aplicar la fundamentación jurídica pertinente en aplicación del principio de iura novit curia, lo debe hacer respetando el derecho de defensa de las partes. Al respecto, se ha señalado que

"el hecho que una de ellas haya invocado una norma jurídica o una fuente del derecho equivocada en modo alguno afecta ese deber. Sin embargo, lo que de ningún modo autoriza ese aforismo, es que el juez aplique un remedio no solicitado o un medio de defensa sustancial no invocado. Cuando se dice que el juez conoce el derecho y puede aplicarlo, se debe entender también que el juez conoce los límites de su decisión - que, por cierto, están impuestos por normas jurídicas-. Estos límites, además, están establecidos en aras de respetar el derecho fundamental a la tutela jurisdiccional efectiva de las partes" (Priori, 2019, pág. 125).

En esa misma línea, el Tribunal Constitucional ha entendido que la decisión sorpresa se encuentra proscrita en nuestro ordenamiento jurídico, pues "la vulneración del principio dispositivo no solo comporta una extralimitación 'en lo resuelto' (que supone, además, una violación del deber de congruencia, como ya quedó dicho), sino también la utilización de un 'argumento' (por el propio juez) que no ha sido objeto de contradicción; un argumento "sorpresivo" (por ser utilizado sin previo 'traslado'), sobre el cual no se le confirió la oportunidad de ser oído" (STC No. 3151-2006-PA, fundamento 12).

Siguiendo la línea del Tribunal Constitucional, la limitación del juez en basar su fallo en un fundamento jurídico distinto al señalado por las partes encuentra su fundamento en el respeto del derecho de defensa y el principio de contradicción, razón por la que si el juez permite a las partes ejercer su derecho de defensa, no existiría impedimento en que realice la modificación de la fundamentación jurídica.

Sobre este punto, es oportuno recalcar que, desde nuestra perspectiva, en muchos casos, en donde las controversias son complejas, el conflicto evoluciona como consecuencia del diálogo dialéctico entre las partes y deja de estar anclado al binomio demanda/contestación. Solo de esta manera podemos entender de una manera más flexible que el principio de iura novit curia resulta incluso necesario como medio que garantice la adecuada prestación de tutela jurisdiccional efectiva. Con esto no estamos diciendo que el principio de congruencia debe ser dejado de lado ni que deba ser flexibilizado, sino que producto del intercambio de información (en un escenario de información asimétrica) es posible entender que el conflicto que empezó de una manera, cambie su caracterización producto del debate y sobre todo, de dicho intercambio.

Dicho ello, consideramos que el momento idóneo en que debería el juez permitir a las partes ejercer su derecho de defensa con relación a una fundamentación jurídica distinta a la planteada debería ser en la fijación de los puntos controvertidos y cuando el juez decida ejercer sus facultades probatorias oficiosas.
En la fijación de los puntos controvertidos, las partes tendrían la posibilidad de presentar las defensas que consideren pertinente y a su vez permitir ser escuchadas oralmente. No por nada en España se ha señalado que "la audiencia previa del juicio ordinario es la fase procesal idónea en la que habría de inscribirse la facultad del juez para advertir a los litigantes de la existencia de otras calificaciones jurídicas, diferentes de las propuestas por el actor y basadas en hechos, narrados en la misma pero que no fueron inicialmente utilizados para fundarla jurídicamente, que podrían conducir a la estimación de la demanda" (Ormazábal, 2007, pág. 123).

Por su parte, la inclusión de medios de prueba que sean producto de los poderes oficiosos del juzgador, indicien necesariamente en la evolución del conflicto que mencionamos líneas arriba, y por ello deberán ser sometidos al contradictorio. De esta manera se garantiza el derecho de defensa de las partes y sobre todo obliga al juzgador a poner de relieve toda cuestión jurídica controvertida que precisamente se derive de dicha "prueba nueva". Solo bajo estas condiciones funciona el principio de iura novit curia.

Por último, y de manera excepcional, el juez debería permitir a las partes ejercer el contradictorio de manera previa a la emisión de la sentencia en caso sea recién en esta etapa en la que detecte que puede existir una fundamentación jurídica distinta. Esto no sería lo ideal, y de hecho sería una incidencia sui generis en el proceso; sin embargo, sería la única forma en la que se evitaría la emisión de una sentencia que atente contra el derecho de defensa de las partes.

\section{Conclusiones}

Lo desarrollado en el presente artículo nos permite darle respuesta al interrogante que planteamos en el título. El Juez conoce el derecho; sin embargo, no puede oponerlo. El principio de iura novit curia debe ser utilizado por el juez de manera respetuosa con los derechos de las partes, teniendo en consideración que son estas las que tiene 
¿El juez conoce el Derecho? Algunos aspectos controversiales con relación a la aplicación del principio de iura novit curia en el proceso civil

Does the judge know the law? Some controversial aspects concerning the application of iura novit curia principle in the Peruvian civil process

el control de lo que se pide y discute en el proceso.

Es por ello durante el proceso se debe de garantizar que las pretensiones planteadas en la demanda (o reconvención) contengan un petitorio claro y preciso. Los casos en los que podrían existir problemas con relación a ello son aquellos en los que el pedido realizado por el demandante podría concederse en razón a diversas casuales establecidas por determinada norma. Los ejemplos clásicos de ello lo constituyen las demandas de nulidad de acto jurídico o de divorcio.

En estos casos, el juez tiene la obligación de garantizar que el petitorio se delimite debidamente y guarde correlación con los hechos constitutivos con los que se identifica. La existencia de pretensiones genéricas, ambiguas o imprecisas podría generar la afectación del principio de imparcialidad y congruencia, así como generar indefensión material en el demandado. Inclusive, la afectación de la proscripción de litispendencia y la vulneración del derecho a la cosa juzgada.

Finalmente, así como el juez tiene proscrito modificar el objeto del proceso y el objeto de debate, también tiene prohibido sorprender con una decisión sustentada en una argumentación jurídica que no fue parte de la controversia. La exigencia de que el proceso se encuentre estructurado respetando el contradictorio, proscribe la posibilidad al juez de imponer una fundamentación jurídica distinta a la que fue materia de debate en el proceso, sin darle a las partes la oportunidad efectiva de pronunciarse sobre ello.

\section{Referencias bibliográficas}

Alsina, H. (1958). Tratado Teórico y práctico de Derecho Procesal Civil y Comercial. Buenos Aires: Ediar.

Ariano Deho, E. (2003).Hacia un proceso civil flexible: critica a las preclusiones rígidas del Código Procesal Civil de 1993". Lima: Ara Editores.

(2013). Un código de fin de siglo: El Código Procesal Civil de 1993. Problemas del procesal civil. Lima: Juristas Editores.
Ariano Deho, E. \& Priori Posada, G. \& (2009). ¿Rechazando la justicia? el derecho de acceso a la justicia y el rechazo liminar de la demanda. Revista THËMIS, 57.

Devis Echandía, H. (1996). Nociones Generales de Derecho Civil. Madrid: Aguilar.

Temis.

(1961). Tratado de Derecho Procesal Civil. Bogotá. Editoria

Expediente No. 1231-2002-PHC (Tribunal Constitucional [Perú], 21 de junio de 2002).

Expediente No. 2465-2004-PA (Tribunal Constitucional [Perú], 11 de octubre de 2004)

Expediente No. 5871-2005-PA/TC (Tribunal Constitucional [Perú], 27 de enero de 2006).

Expediente No. 6149-2006-PA (Tribunal Constitucional [Perú], 11 de diciembre de 2006).

Expediente No. 4295-2007-PHC (Tribunal Constitucional [Perú], 22 de setiembre de 2008).

Expediente No. 3151-2006-PA (Tribunal Constitucional [Perú], 21 de octubre de 2008).

Ezquiaga Ganuzas, F. (2000). Iura Novit Curia y la aplicación judicial del derecho. Valladolid: Editorial Lexonova.

González Álvarez, R. (2013). Neoprocesalismo. Teoría del proceso civil eficaz. Lima: Ara editores.

Liebman, E. T. (1980). Manual de Derecho procesal Civil. Buenos Aires: EJEA.

Marinoni, Luis Guillermo (2007). Derecho fundamental a la tutela jurisdiccional efectiva. Lima: Palestra Editores.

Monroy Gálvez, J. (2010). Comentarios al Art. X del Título Preliminar del Código Civil. Código Civil Comentado, Tomo I, Lima: Gaceta Jurídica, 2010.

(2009). Teoría General del Proceso. Lima: Communitas.

Montero Aroca, J., Gómez Colomer, J, y Barona Vilar, S. (2014). Derecho Jurisdiccional I. Parte General. Valencia: Tirant lo Blanch.

Nieva Fenoll, J. (2015). Derecho procesal (Tomo II). Madrid: Marcial Pons.

Ormazábal Sánchez, G. (2007). Iura Novit Curia. La vinculación del juez a la calificación jurídica de la demanda. Madrid: Marcial Pons.

Palacio Pareja, E. (1996). La fijación de puntos controvertidos en la metodología de la investigación jurídica. Ponencias del I Congreso de Derecho Procesal. Pontificia Universidad Católica del Perú. Lima.

Prado Bringas, R. \& Zegarra Valencia, F. (2016) Litisconsorcio e intervención de terceros. Buscando una nueva aproximación. Revista Ius Et Veritas, 56

Priori Posada, G. (2019). El proceso y la tutela de los derechos. Lima: Fondo Editorial PUCP.

Taruffo, M. "La prueba de los hechos". (Bologna: Trotta, 2005).

Zufaleto, C. (2017). La dimensión de la «prohibición de la decisiónsorpresa» a partir del principio de contradicción en la experiencia brasileña y el nuevo Código Procesal Civil de 2015: reflexiones de cara al derecho peruano. Revista Derecho PUCP,78. 